\title{
SEVERIDADE DA ANTRACNOSE E PERDA DE MATÉRIA FRESCA DE FRUTOS DE DEZ PROCEDÊNCIAS DE MARACUJÁZEIRO-DOCE (Passiflora alata Dryander) EM DOIS AMBIENTES DE ARMAZENAMENTO ${ }^{1}$
}

\author{
NILTON TADEU VILELA JUNQUEIRA ${ }^{3}$, RODRIGO MARQUEZ ANSELMO ${ }^{2}$, ALBERTO CARLOS DE QUEIROZ \\ PINTO $^{3}$, VICTOR HUGO VARGAS RAMOS ${ }^{3}$, AILTON VITOR PEREIRA ${ }^{3}$, ALESSANDRA CARNEIRO DO \\ NASCIMENTO ${ }^{2}$
}

\begin{abstract}
RESUMO - Frutos de maracujá-doce de dez procedências foram avaliados quanto à severidade da antracnose (Colletotrichum gloeosporioides Penz.) e quanto à perda de matéria fresca em dois ambientes de armazenamento: câmara fria $\left(5^{\circ} \mathrm{Ce} \mathrm{UR} \mathrm{de} 90 \%\right)$ e em ambiente de sala $\left(23 \pm 1^{\circ} \mathrm{C}\right.$ e UR de $65 \pm 5 \%$ ). Plantas provenientes de frutos colhidos em estado nativo ou adquiridos nos mercados da Central de Abastecimento de São Paulo- CEAGESP, procedências A, B e C; Viçosa-MG, procedência D; Tomé-Açu-PA, procedência E; Itacoatiara-AM, procedência F; Ouro Preto d'Oeste-RO, procedência G; Domingos Martins-ES, procedência H; Pontes e Lacerda-MT, procedência I; e Rondonópolis-MT, procedência J, foram estabelecidas no Distrito Federal. Após as primeiras colheitas, a melhor planta de cada procedência, selecionada pela maior taxa de vingamento, coloração da casca, tamanho do fruto e menor espessura de casca, foi multiplicada por estaquia. Frutos de três plantas clonadas de cada procedência, obtidos por polinização natural, foram colhidos de vez e mantidos em caixas de papelão padrão. As avaliações do percentual de perda de matéria fresca foram efetuadas no dia da colheita (tempo zero), aos 3; 6; 9 e 12 dias após, enquanto a severidade da antracnose (\% da superfície do fruto ocupada por lesões) e incidência (\% de frutos atacados) de outras doenças foram quantificadas aos 12 dias de armazenamento. As procedências com menores índices de antracnose foram a I e G. Os frutos armazenados em câmara fria foram menos afetados pela doença. As procedências $\mathrm{G}$ e $\mathrm{A}$ foram as que, ao final dos doze dias de armazenamento, perderam menos matéria fresca sendo, respectivamente, de 16,68\% e 17,86\% em ambiente de sala e de 7,71 e 6,61\% em câmara fria. Considerando-se a média de todas as procedências, aos 12 dias de armazenamento, a menor perda de matéria fresca $(9,78 \%)$ ocorreu em câmara fria, contra 22,06\% em ambiente de sala. As procedências A, E, F, G e J perderam menos matéria fresca em ambiente natural que as demais.
\end{abstract}

Termos para indexação: Colletotrichum gloeosporioides, doenças de pós-colheita, resistência à antracnose.

\section{SEVERITY OF ANTHRACNOSE AND FRESH WEIGHT LOSSES OF SWEET PASSION FRUITS (Passiflora alata Dryander) FROM TEN ORIGINS, STORED IN TWO ENVIRONMENTAL CONDITIONS}

\begin{abstract}
Sweet passion fruit (Passiflora alata Dryander) from ten different sources were evaluated for the severity of anthracnose (Colletotrichum gloeosporioides Penz.) and their fresh weight losses when stored in two environmental conditions: cold storage $\left(5^{\circ} \mathrm{C}\right.$ and $90 \%$ R.H.) and room temperature $\left(23 \pm 1{ }^{\circ} \mathrm{C}\right.$ and $65 \pm 5 \%$ R.H.). Seed plants were established from ten sources proceeding from the Central of Food Supply of São Paulo State - CEAGESP (sources A, B e C), Viçosa-MG (source D), Tomé-Açu-PA (source E), Itacoatiara-AM (source F), Ouro Preto d'Oeste-RO (source G), Domingos Martins-ES (source H), Pontes e Lacerda-MT (source I), Rondonópolis-MT (source J) and stem cuttings were collected from the best plants to produce the asexual matrix plants. Unriped fruits produced in Distrito Federal, Brazil, were harvested from plants obtained by stem-rooted cuttings. All origins were collected in wild conditions, except A, B, C and E sources. Fruit evaluations were done by determining their weight fresh matter after 0, 3, 6, 9 and 12 days after harvesting, whereas the anthracnose severity (\% of fruit area with lesions) and incidence (\% of infected fruits) of other diseases were evaluated after 12 days of storage. The anthracnose was less severe on fruits from sources I and G, however, this disease shown less severe attack when fruits were stored in cold conditions. After 12 days of storage at room temperature, the fruit sources G and A, had fresh matter losses of $16,68 \%$ and $17,86 \%$ while in cold storage the fresh matter losses were $7,71 \%$ and $6,61 \%$, respectively. The percentage of fresh matter loss of G, A, E, J and F fruit sources was less in room temperature when compared with other sources. It was observed after 12 days at cold storage, that the fresh matter loss shown an average of $9,78 \%$, which is approximately twice lower the storage at room temperature $(22,06 \%)$.
\end{abstract}

Index terms: post-harvest disease, anthracnose resistance, Colletotrichum gloeosporioides,

\section{INTRODUÇÃO}

O maracujá-doce é uma das espécies nativas do Brasil, de ocorrência bastante generalizada, podendo ser encontrado nas regiões Norte (AM, RO, PA e TO), Nordeste (BA, MA e PI), Sudeste (MG, ES, SP e RJ), Centro-Oeste ( DF, GO, MT e MS) e Sul (RS e PR). É vulgarmente conhecido como maracujá-de-refresco, maracujá-grande, maracujá-alado, maracujá-guaçu, maracujá-de-comer. Segundo Oliveira et al. (1980), Vasconcellos et al. (2001), essa espécie de maracujazeiro apresenta boa adaptação às diferentes condições edafoclimáticas, podendo ser cultivado de norte a sul do País. Suas características quanto ao tamanho, à coloração externa, aroma, propriedades medicinais e baixa acidez tornam-no bastante aceitável pelos consumidores europeus e indicam-no como uma opção para exportação (Ruggiero et al., 1996; Vasconcelos \& Cereda, 1994; Vasconcellos et al., 2001).

O maracujá-doce vem, a cada ano, ganhando mais espaço no mercado das frutas para consumo "in natura". Segundo Vasconcellos et al. (2001), o volume de maracujá-doce comercializado na CEAGESP dobrou nos últimos cinco anos, passando de 230.000 caixetas de $3,5 \mathrm{~kg}$ em 1994, para 450.00 em 1998. Segundo Kavati et al. (1998), citado por Vasconcellos et al. (2001), a área cultivada no Estado de São Paulo é de aproximadamente 200 hectares, com uma produtividade média de 25 a 30 toneladas/ha. No Distrito Federal, Veras (1997) obteve produtividade de $29,9 \mathrm{~kg}$ por planta/ano em um pomar irrigado, o que corresponde a 29,9 t/ ha numa densidade de 1000 plantas por hectare.

Embora seja uma fruta de grande potencial de mercado, maracujá-doce apresenta vários problemas. Além das dificuldades para produzi-lo, devido ao ataque de pragas e doenças (Anselmo \& Junqueira, 1997; Rangel \& Junqueira, 1998, Vasconcellos et al., 2001), é uma fruta perecível e muito sensível ao armazenamento e ao transporte, além de apresentar casca espessa e baixo rendimento de polpa (Veras, 1997, Ruggiero et al., 1996).

A literatura, de modo geral, relata a alta perecibilidade e susceptibilidade do maracujá-doce às doenças que ocorrem na pós-colheita

\footnotetext{
${ }^{1}$ (Trabalho 060/2002). Recebido: 08/04/2002; Aceito para publicação: 25/03/2003.

2 Pesquisadores da Embrapa Cerrados, Caixa Postal 08223, CEP 73301-970, Planaltina-DF.

${ }^{3}$ Estudantes de Mestrado em Fitotecnia na FAV/Universidade de Brasília, Caixa Postal 04508, CEP 70.910-970, Brasília - DF, bolsistas do CNPq
} 
(Rangel \& Junqueira, 1998; Anselmo \& Junqueira, 1997), principalmente à antracnose causada por Colletotrichum gloeosporioides, mas não faz qualquer menção às técnicas de armazenamento e aos tipos de embalagens, bem como ao comportamento de frutos de diferentes procedências ou cultivares.

Dessa forma, este estudo teve como objetivo, avaliar a severidade da antracnose e a perda de matéria fresca em câmara fria $\left(5^{\circ} \mathrm{C}\right.$ e UR de $90 \%)$ e em ambiente de sala $\left(23 \pm 1^{\circ} \mathrm{C}\right.$ e UR de $\left.65 \pm 5 \%\right)$ em frutos de dez procedências de maracujazeiro-doce.

\section{MATERIALEMÉTODOS}

Os frutos foram obtidos de uma coleção de maracujazeiro-doce, situada no Núcleo Jardim II, Distrito Federal, distante cerca de $70 \mathrm{~km}$ de Brasília. O pomar, irrigado por sistema de gotejamento, situa-se a $47^{\circ}$ $25^{\prime} \mathrm{W}$ de longitude e $15^{\circ} 58^{\prime} \mathrm{S}$ de latitude, e acerca de 860 metros de altitude, precipitação média anual de 1000 milímetros. A temperatura média anual é de $21,9^{\circ} \mathrm{C}$, com máxima de $27,4^{\circ} \mathrm{C}$, e mínima de $16,3^{\circ} \mathrm{C}$. A umidade relativa média é de $69 \%$, com o período mais seco entre agosto e setembro e o mais úmido entre dezembro e abril. A luminosidade mínima (fotoperíodo) diária é de cerca de 11 horas e 18 minutos, aproximadamente, de sol, no período de 15 de junho a 15 de julho.

O solo, onde a coleção está implantada, é um gleissolo hálico, drenado artificialmente, textura argilosa (53\% de argila), o qual recebeu tratamentos de calagem e fosfatagem um ano antes do plantio. A análise química de amostra do solo antes do plantio revelou um solo levemente ácido com $\mathrm{pH}$ em água de 5,$9 ; \mathrm{Al}=0,02 \mathrm{meq} / 100 \mathrm{~cm}^{3} ; \mathrm{Ca}+\mathrm{Mg}=5,65 \mathrm{meq} /$ $100 \mathrm{~cm}^{3} ; \mathrm{P}=16,40$ ppm; $\mathrm{K}=96,8$ ppm; $\mathrm{Fe}=97,2 \mathrm{ppm} ; \mathrm{Cu}=1,20$ ppm; $\mathrm{Zn}=$ $1,62 \mathrm{ppm} ; \mathrm{Mn}=3,44 \mathrm{ppm} ; \mathrm{Mo}=1,6 \mathrm{ppm}$, e teor de matéria orgânica de 2,6\%.

As procedências estudadas foram, inicialmente, obtidas de frutos adquiridos em mercados da CEAGESP (procedências A, B e C) e de plantações comerciais de Tomé-Açu-PA (procedência E). As demais, coletadas em estado nativo, oriundas de Viçosa-MG (procedência D), Itacoatiara-AM (procedência F), Ouro Preto d` Oeste-RO (procedência G), Domingos Martins-ES (procedência H), Pontes e Lacerda-MT (procedência I) e Rondonópolis-MT (procedência J). Após um ano de produção no Distrito Federal, a melhor planta de cada procedência, selecionada com base no tamanho e formato do fruto, coloração da polpa amarela ou laranja e espessura da casca, foi reproduzida por estaquia. As estacas, com três nós, foram retiradas da parte mediana de ramos durante o mês de julho, implantadas em sacos de polietileno contendo substrato comercial (Plantmax horta) à base de vermiculita, casca de madeira e fertilizantes N, P e K. As plantas propagadas por estacas foram plantadas na mesma área, três por procedência e intercaladas com outras plantas de maracujá-doce oriundas de sementes ilegítimas. A polinização das flores ocorreu naturalmente.

Os frutos das plantas clonadas foram colhidos de vez, numerados e acondicionados em caixas de papelão padrão. Uma caixa, contendo oito frutos de cada procedência, foi mantida em câmara fria a $5^{\circ} \mathrm{C}$ e umidade relativa de $90 \%$; a outra, em uma pequena sala fechada, com condicionador de ar, a $23 \pm 1^{\circ} \mathrm{C}$ e umidade relativa de $65 \pm 5 \%$, nas dependências da Embrapa Cerrados. O experimento foi conduzido em 1998 e repetido em 1998 e 1999. O delineamento experimental foi o inteiramente casualizado, com oito repetições de um fruto por parcela, sendo cada experimento analisado separadamente.

As avaliações foram efetuadas aos $0 ; 3 ; 6 ; 9$ e 12 dias de armazenamento, determinando-se, em porcentagem, a perda de matéria fresca calculada pela diferença de peso dos frutos em balança de precisão, entre cada tempo de permanência e o peso inicial. Também foram avaliadas: a severidade (\% da superfície do fruto ocupada com lesões) da antracnose e a incidência (\%de frutos atacados) de outras doenças, aos 12 dias de armazenamento. Para a confirmação das doenças e identificação dos patógenos presentes, utilizaram-se exames microscópicos. A severidade da antracnose foi calculada com base no número de lesões por fruto e o diâmetro dessas lesões. Com esses dados, calculou-se a área lesada na superfície de cada fruto. Para calcular a porcentagem da superfície do fruto coberta por lesões, determinou-se a área de cada fruto aos 12 dias de armazenamento, seccionando sua casca em vários quadrados ou retângulos que foram pressionados sobre um plano, para que fossem dimensionados. A área do fruto foi determinada pelo somatório das áreas seccionadas nas formas de quadrados e retângulos.

\section{RESULTADOS E DISCUSSÃO}

A antracnose causada por Colletotrichum gloeosporioides foi a doença mais freqüente, com $100 \%$ de incidência. Constataram-se também a podridão-preta ou peduncular (Botryodiplodia theobromae), com uma incidência de 8,3\%, podridão-mole causada por Gliocladium roseum, Rhizopus stolonifer e Sclerotium rolfsii, com incidência de 3\%, manchas e/ou apodrecimento causados por Alternaria passiflorae e Alternaria sp. com uma incidência de $5,4 \%$ e mancha bacteriana (Xanthomonas campestris pv. passiflorae) com uma incidência de 6,3\%, já relatadas por Anselmo \& Junqueira (1997).

Nas Tabelas 1 e 2, estão apresentados os dados referentes à severidade da antracnose e perda de matéria fresca nos frutos armazenados em câmara fria e em ambiente de sala. Analisando-se a Tabela 1, verifica-se que, em ambiente de sala $\left(23 \pm 1^{\circ} \mathrm{C}\right.$ e UR de $\left.65 \pm 5 \%\right)$, após 12 dias de armazenamento, a antracnose foi menos severa nas procedências I, G e J, com destaque para a procedência I. Em frutos armazenados em câmara fria a $5^{\circ} \mathrm{C}$ e UR de $90 \%$, a severidade da antracnose após 12 dias de armazenamento, de modo geral, foi bem menor que nos frutos armazenados em ambiente de sala (Tabela 2). Nessa temperatura, a colonização dos tecidos e a esporulação de C. gloeosporioides são reduzidas (Bailey $\&$ Jeger, 1992). Nestas condições, o índice da antracnose foi menor nos frutos das procedências I, G e D, com destaque para a procedência I. Verifica-se, nas Tabelas 1 e 2, que a antracnose foi mais severa nas procedências A, B e C, as mais cultivadas comercialmente no Estado de São Paulo, quando estas foram armazenadas em ambiente natural ou em câmara fria. Na literatura, estão relatadas as principais doenças do maracujá-doce (Rezende \& Junqueira, 1997; Anselmo \& Junqueira, 1997; Rangel \& Junqueira, 1998; Ruggiero et al. 1996), mas não há qualquer menção à resistência de cultivares ou de germoplasma de maracujá-doce à antracnose para fazer-se uma comparação de resultados. No entanto, analisando-se os resultados obtidos neste experimento, pode-se admitir a existência de material genético promissor em termos de resistência à antracnose em pós-colheita.

TABELA 1- Severidade da antracnose aos 12 dias e percentual de perda de matéria fresca em frutos de maracujá-doce de dez procedências, armazenados em ambiente de sala a $23 \pm 1^{\circ} \mathrm{C}$ e umidade relativa de $65 \pm 5 \%$.

\begin{tabular}{ccccccc}
\hline $\begin{array}{c}\text { Procedências } \\
\text { de } \\
\text { maracujá-doce }\end{array}$ & $\begin{array}{c}\text { *Severidade da } \\
\text { antracnose (\%) }\end{array}$ & \multicolumn{4}{c}{$\begin{array}{c}\text { Tempo de armazenamento (dias) } \\
\text { e Perda de matéria fresca (\%) }\end{array}$} \\
\hline & & 0 & 3 & 6 & 9 & 12 \\
A & $33,6 \mathrm{a}$ & 0 & 3,4 & 6,8 & 12,2 & $17,9 \mathrm{~d}$ \\
$\mathrm{~B}$ & $29,8 \mathrm{ab}$ & 0 & 5,6 & 11,4 & 18,2 & $25,2 \mathrm{ab}$ \\
C & $24,3 \mathrm{bc}$ & 0 & 5,4 & 10,7 & 17.0 & $24,0 \mathrm{abc}$ \\
D & $14,5 \mathrm{~cd}$ & 0 & 6,2 & 12,5 & 20,6 & $31,2 \mathrm{a}$ \\
E & $38,2 \mathrm{a}$ & 0 & 4,5 & 8,7 & 14,1 & $20,6 \mathrm{~cd}$ \\
F & $20,3 \mathrm{c}$ & 0 & 4,2 & 8,6 & 13,3 & $20,0 \mathrm{~cd}$ \\
G & $11,3 \mathrm{de}$ & 0 & 3,8 & 7,6 & 11,6 & $16,7 \mathrm{~d}$ \\
H & $25,4 \mathrm{abc}$ & 0 & 3,7 & 12,3 & 17,1 & $22,4 \mathrm{bc}$ \\
I & $9,8 \mathrm{e}$ & 0 & 4,5 & 10 & 16 & $24,3 \mathrm{bc}$ \\
J & $11,3 \mathrm{de}$ & 0 & 4,8 & 9,1 & 13,8 & $18,5 \mathrm{bc}$ \\
\hline Média & -- & -- & 4,61 & 9.77 & 15,4 & 22,06 \\
CV \% & 13,76 & & & & & 13,55 \\
\hline
\end{tabular}

Os dados são referentes à média de oito frutos por procedência em cada ambiente. * Severidade $=$ percentagem da superfície do fruto ocupada por lesões aos 12 dias de armazenamento.

Médias seguidas pela mesma letra não diferem entre si, pelo teste de Tukey, ao nível de $1 \%$ 
TABELA 2- Severidade da antracnose aos 12 dias e percentual de perda de matéria fresca em frutos de maracujá-doce de dez procedências, armazenados em câmara fria a $5{ }^{\circ} \mathrm{C}$ e umidade relativa de $90 \%$.

\begin{tabular}{ccccccc}
\hline $\begin{array}{c}\text { Procedências } \\
\text { de } \\
\text { maracujá-doce }\end{array}$ & $\begin{array}{c}\text { *Severidade da } \\
\text { antracnose (\%) }\end{array}$ & \multicolumn{4}{c}{$\begin{array}{c}\text { Tempo de armazenamento (dias) } \\
\text { e Perda de matéria fresca (\%) }\end{array}$} \\
\hline \multicolumn{1}{c}{} & & 0 & 3 & 6 & 9 & 12 \\
A & $6,2 \mathrm{abc}$ & 0 & 1,7 & 3,3 & 5,0 & $6,6 \mathrm{~d}$ \\
$\mathrm{~B}$ & $7,1 \mathrm{a}$ & 0 & 2,9 & 5,5 & 8,5 & $11,3 \mathrm{ab}$ \\
C & $4,8 \mathrm{bc}$ & 0 & 2,4 & 4,6 & 6,6 & $8,9 \mathrm{abcd}$ \\
D & $3,6 \mathrm{de}$ & 0 & 3,1 & 6,1 & 8,9 & $11,9 \mathrm{a}$ \\
E & $6,8 \mathrm{ab}$ & 0 & 2,7 & 5,1 & 7,2 & $9,6 \mathrm{abc}$ \\
F & $4,6 \mathrm{bc}$ & 0 & 2,9 & 5,7 & 8,4 & $11,3 \mathrm{abc}$ \\
G & $2,8 \mathrm{de}$ & 0 & 2,1 & 3,9 & 5,8 & $7,7 \mathrm{~cd}$ \\
H & $5,9 \mathrm{~b}$ & 0 & 2,9 & 5,9 & 9,0 & $13,4 \mathrm{a}$ \\
I & $2,2 \mathrm{e}$ & 0 & 2,2 & 4,2 & 6,2 & $8,2 \mathrm{bcd}$ \\
J & $3,9 \mathrm{~cd}$ & 0 & 2,3 & 4,5 & 6,5 & $8,9 \mathrm{abcd}$ \\
\hline Média & -- & -- & 2,52 & 4,88 & 7,21 & 9,78 \\
CV \% & 9,76 & & & & & 13,05 \\
\hline
\end{tabular}

Os dados são referentes à média de oito frutos por procedência em cada ambiente. * Severidade $=$ percentagem da superfície do fruto ocupada por lesões aos 12 dias de armazenamento.

Médias seguidas pela mesma letra não diferem entre si, pelo teste de Tukey, ao nível de $1 \%$.

Quanto à perda de matéria fresca, notam-se diferenças significativas entre as procedências (Tabelas $1 \mathrm{e}$ 2). Algumas como a B, C e I perderam mais de $24 \%$ de matéria fresca em 12 dias de armazenamento em ambiente de sala a $23 \pm 1^{\circ} \mathrm{C}$ e umidade relativa de $65 \pm 5 \%$ (Tabela 1). Por sua vez, as procedências $\mathrm{G}$, J e A foram as que menos perderam peso durante os 12 dias de armazenamento. A procedência $\mathbf{G}$ apresentou, no final desses 12 dias, $16,68 \%$ de perda de matéria fresca, índice muito inferior ao da procedência $\mathbf{D}$, com $31,16 \%$, o que representa quase o dobro de perda. Em todos os períodos de permanência, as perdas de matéria fresca nos frutos armazenados em local a $23 \pm 1^{\circ} \mathrm{C}$ e umidade relativa de $65 \pm 5 \%$ foram, em média, bem superiores às perdas obtidas nos frutos mantidos em câmara fria. Não houve diferenças significativas ao nível de $5 \%$, entre as perdas de matéria fresca ocorridas entre os períodos de armazenamento dentro de um mesmo ambiente. Em ambiente de sala, essa perda variou, em média, de $4,61 \%$ entre o tempo 0 e 3 dias a 6,66\% entre 9 e 12 dias (Tabela 1). Em câmara fria, essa perda variou de $2,52 \%$ entre o tempo 0 e 3 dias a 2,57\% entre o tempo 9 e 12 dias (Tabela 2). Esses resultados indicam que as procedências mantiveram a mesma tendência de perda de matéria fresca aos 3;6;9 e 12 dias de armazenamento. É importante considerar que, de acordo com os dados obtidos nesse experimento, o maracujá-doce, independentemente de procedências, perdeu aproximadamente $5,5 \%$ de seu peso a cada três dias, quando armazenado em ambiente de sala, e 2,44\%, quando armazenado em câmara fria, a $5^{\circ} \mathrm{C}$ e umidade relativa de $90 \%$.

Em termos econômicos, considerando-se uma produção de $10.000 \mathrm{~kg}$ de maracujá-doce, o produtor perde a cada três dias de armazenamento, em condições de ambiente, aproximadamente $550 \mathrm{~kg}$, contra $244 \mathrm{~kg}$ se armazenado em câmara fria.

\section{CONCLUSÕES}

1) Em câmara fria $\left(5^{\circ} \mathrm{C}\right.$ e umidade relativa de $\left.90 \%\right)$, as procedências que apresentaram menores índices de antracnose, após 12 dias de armazenamento, foram a I(Pontes e Lacerda-MT), G(Ouro Preto d'OesteRO) e D(Viçosa-MG), com destaque para procedência I.
2) Em ambiente de sala $\left(23 \pm 1^{\circ} \mathrm{C}\right.$ e umidade relativa de $\left.65 \pm 5 \%\right)$, as procedências que apresentaram menores índices de antracnose, após 12 dias de armazenamento, foram a I (Pontes e Lacerda-MT), G (Ouro Preto d'Oeste-RO) e J (Rondonópolis-MT), com destaque para procedência I.

3) Frutos armazenados em câmara fria foram menos afetados pela antracnose.

4) Frutos armazenados em câmara fria tiveram, em média, após 12 dias de armazenamento, a menor perda de matéria fresca.

5) As procedências de Ouro Preto d'Oeste - RO (G) e CEAGESP (A) foram as que, ao final dos 12 dias de armazenamento, perderam menos matéria fresca.

\section{REFERÊNCIASBIBLIOGRÁFICAS}

ANSELMO, R. M.; JUNQUEIRA N. T. V. Doenças de Maracujá-doce (Passiflora alata Dryander) em pós-colheita. In: CONGRESSO BRASILEIRO DE FITOPATOLOGIA, 30. 1997, Poços de Caldas-MG. Fitopatologia brasileira, Brasília, v.22, suplemento, 1997.

ANSELMO, R. M.; JUNQUEIRA, N. T. V. Doenças de Maracujá-doce (Passiflora alata Dryander). In: SIMPÓSIO BRASILEIRO DA CULTURA DO MARACUJAZEIRO, 7., 1998, Jaboticabal. Anais... v.1, p. 360-362.

BAILEY, J.A.; JEGER, M.J. Colletotrichum: Biology, pathology and control. Oxford, UK: British Society for Plant pathology, 1992.388p.

OLIVEIRA, J. C.; SALOMÃO, T. A.; RUGGIERO. C.; ROSSINI, A.C. Observações sobre o cultivo de $P$. alata (maracujá-guaçu). Revista Brasileira de Fruticultura, Campinas-SP, v.2, n.1, p.59-63, 1980.

RANGEL, L.E. P.; JUNQUEIRA, N. T. V. Determinação do período de susceptibilidade do maracujá-doce (Passiflora alata Dryand) às principais doenças em pré-colheita. In: CONGRESSO DE INICIAÇÃO CIENTÍFICA DA UNIVERSIDADE DE BRASÍLIA, 5., 1999, Brasília, CONGRESSO DE INICIAÇÃO CIENTÍFICA DA UnB, 5, 1999, Brasília Anais... Universidade de Brasília, 1999.

RANGEL, L. E. P.; JUNQUEIRAN. T. V. Efeito de fungicidas no controle de doenças de Maracujá-doce (Passiflora alata Dryander) em póscolheita. In: SIMPÓSIO BRASILEIRO DA CULTURA DO MARACUJAZEIRO, 7., 1998, Jaboticabal. Anais... v.1, p.363-364.

REZENDE, D.V; JUNQUEIRAN.T.V. Queda de flores de Maracujá-doce (Passiflora alata Dryander) provocada por Rhizopus stolonifer Sac. Fitopatologia Brasileira, resumos do $30^{\circ}$ Congresso Brasileiro de Fitopatologia, 1997, Poços de Caldas-MG.

RUGGIERO, C; SÃO JOSE, A.R; VOLPE, C.A; OLIVEIRA, J.C; DURIGAN, J. F; BAUMGARTNER, J. G; SILVA, J.R ,da; NAKAMURA, K.I.; FERREIRA, M.E.; KAVATI, R.; PEREIRA, V.P. Maracujá para exportação: aspectos técnicos da produção. Brasília: MAARA/ SDR-FRUPEX, Embrapa-SPI, 1996. 64p. (Publicações Técnicas Frupex, 19).

VASCONCELLOS, M.A.; BRANDÃO FILHO, J.U.T.; VIEITES, R.L. Maracujá-doce. In: BRUKNER, C.H.; PICANÇO, M.C. (Ed.). Maracujá: Tecnologia de produção, Pós-colheita, Agroindústria, Mercado. Porto Alegre: Cinco Continentes, 2001. p. 387-408.

VASCONCELLOS, M.A. da S.; CEREDA, E. O cultivo do maracujá-doce. In: SÃO JOSÉ, A.R. (Ed.). Maracujá: produção e mercado. Vitória da Conquista: DFZ/UESB, 1994. p.71-83.

VERAS, M. C. M. Fenologia, produção e caracterização físico-química dos frutos de maracujazeiro-ácido (Passiflora edulis f. flavicarpa Deg.) e doce (Passiflora alata Dryander) nas condições de Cerrado de Brasília-DF, 1997. 105f. Dissertação (Mestrado em Fitotecnia), Universidade Federal de Lavras, Lavras-MG, 1997. 